\title{
Theoretical considerations on programmatic assessment
}

Citation for published version (APA):

Torre, D. M., Schuwirth, L. W. T., \& Van der Vleuten, C. P. M. (2020). Theoretical considerations on programmatic assessment. Medical Teacher, 42(2), 213-220.

https://doi.org/10.1080/0142159X.2019.1672863

Document status and date:

Published: 01/02/2020

DOI:

10.1080/0142159X.2019.1672863

Document Version:

Publisher's PDF, also known as Version of record

Document license:

Taverne

Please check the document version of this publication:

- A submitted manuscript is the version of the article upon submission and before peer-review. There can be important differences between the submitted version and the official published version of record.

People interested in the research are advised to contact the author for the final version of the publication, or visit the DOI to the publisher's website.

- The final author version and the galley proof are versions of the publication after peer review.

- The final published version features the final layout of the paper including the volume, issue and page numbers.

Link to publication

\footnotetext{
General rights rights.

- You may freely distribute the URL identifying the publication in the public portal. please follow below link for the End User Agreement:

www.umlib.nl/taverne-license

Take down policy

If you believe that this document breaches copyright please contact us at:

repository@maastrichtuniversity.nl

providing details and we will investigate your claim.
}

Copyright and moral rights for the publications made accessible in the public portal are retained by the authors and/or other copyright owners and it is a condition of accessing publications that users recognise and abide by the legal requirements associated with these

- Users may download and print one copy of any publication from the public portal for the purpose of private study or research.

- You may not further distribute the material or use it for any profit-making activity or commercial gain

If the publication is distributed under the terms of Article $25 \mathrm{fa}$ of the Dutch Copyright Act, indicated by the "Taverne" license above, 


\title{
Theoretical considerations on programmatic assessment
}

\author{
Dario M. Torre, L. W. T. Schuwirth \& C. P. M. Van der Vleuten
}

To cite this article: Dario M. Torre, L. W. T. Schuwirth \& C. P. M. Van der Vleuten (2020) Theoretical considerations on programmatic assessment, Medical Teacher, 42:2, 213-220, DOI: 10.1080/0142159X.2019.1672863

To link to this article: https://doi.org/10.1080/0142159X.2019.1672863

\section{Published online: 17 Oct 2019.}

\section{Submit your article to this journal $₫$}

\section{Џll Article views: 1683}

Q View related articles $₫$

View Crossmark data $₫$

Citing articles: 14 View citing articles 주다. 


\title{
Theoretical considerations on programmatic assessment
}

\author{
Dario M. Torre ${ }^{\text {a }}$ L. W. T. Schuwirth ${ }^{\text {b }}$ (D) and C. P. M. Van der Vleuten ${ }^{c, d}$ (D) \\ ${ }^{a}$ Department of Medicine, Uniformed Services University of Health Sciences, Bethesda, MD, USA; ${ }^{b}$ Department of Education and Health \\ Profession Education, Flinders Medical School, Adelaide, Australia; 'Department of Educational Development and Research, Maastricht \\ University, Maastricht, The Netherlands; ${ }^{d}$ Faculty of Health Medicine and Life Sciences, School of Health Professions Education, \\ Maastricht University, Maastricht, The Netherlands
}

\begin{abstract}
Introduction: Programmatic assessment (PA) is an approach to assessment aimed at optimizing learning which continues to gain educational momentum. However, the theoretical underpinnings of PA have not been clearly described. An explanation of the theoretical underpinnings of PA will allow educators to gain a better understanding of this approach and, perhaps, facilitate its use and effective implementation. The purpose of this article is twofold: first, to describe salient theoretical perspectives on PA; second to examine how theory may help educators to develop effective PA programs, helping to overcome challenges around PA.

Results: We outline a number of learning theories that underpin key educational principles of PA: constructivist and social constructivist theory supporting meaning making, and longitudinality; cognitivist and cognitive development orientation scaffolding the practice of a continuous feedback process; theory of instructional design underpinning assessment as learning; self-determination theory (SDT), self-regulation learning theory (SRL), and principles of deliberate practice providing theoretical tenets for student agency and accountability.

Conclusion: The construction of a plausible and coherent link between key educational principles of PA and learning theories should enable educators to pose new and important inquiries, reflect on their assessment practices and help overcome future challenges in the development and implementation of PA in their programs.
\end{abstract}

\section{Introduction}

Programmatic assessment (PA) is an approach to assessment in which assessment is seen as a system or a program as a whole (Van der Vleuten and Schuwirth 2005). It uses a deliberate mix of methods to achieve optimal constructive alignment (Biggs 1996). Each individual assessment in PA is merely a data point which is typically optimized for learning. This means that pass/fail decisions are not taken per data point, but only after enough information across data points has been collected. In PA, selfregulated learning is promoted by periodic reflection by the learners on the information received from the data points and with coaches (faculty members who gather and use performance data to stimulate and support students in managing their learning) who regularly discuss the learner's progression. Only when sufficient data are collected, a summative decision is taken, usually in the form of an (independent) committee of assessors (see Table 1 for an overview of the core aspects of PA). In almost all cases, PA is associated with a so-called assessment for learning philosophy (Schuwirth and Van der Vleuten 2011).

The PA has been implemented in several educational programs (Wilkinson et al. 2011; Driessen et al. 2012; Bok et al. 2013; Roberts et al. 2014; Olupeliyawa and Balasooriya 2015; Heeneman et al. 2017; Jamieson et al. 2017) and is continuing to gain educational momentum. However, the theoretical underpinnings of PA have not been clearly described. This is surprising as the importance of theories behind educational or assessment approaches is recognized increasingly as essential in medical education. This is for various reasons. The first and most obvious reason is that, like any scientific domain, the science behind medical education progresses through experimental testing of theories and their ensuing hypotheses. Another important reason is that theories are important for making sense of research findings and that understanding why certain phenomena occur allows educators to adapt research findings from one educational context to another (Cianciolo et al. 2013). Therefore, we feel that an in-depth description of the theoretical tenets of PA will allow educators to gain a better understanding of this approach and, perhaps, facilitate its use and effective implementation. Further, it will provide new insights into the basic structure of the PA model and contribute to predict and explain educational phenomena (Prochaska et al. 2008). As stated in an old aphorism, 'there is nothing more practical than a good theory' (Lewin 1951).

The purpose of this article is therefore twofold: first, to describe salient theoretical perspectives on PA; second to examine how theory may help educators to develop effective PA programs, enhance students' learning and growth, and ultimately help overcome challenges around PA.

We want to express a caveat here. The purpose of this article is not to argue that one particular theory is better than others to explain the tenets of PA. We admit that we have chosen to use our views on what theories explain which tenets most insightfully. This means that we may have left out theories that others might find important or may have included theories that others find less useful. 


\section{Practice points}

- Meaning and meaning making play a central role in PA. In a constructivist approach, learning is seen as an active process of meaning making that is internally constructed based on prior knowledge and understanding.

- The continuity of the experience with constant delivery of feedback, the role of teachers in coaching and mentoring students, and the social interdependence and interactions among assessors are elements of PA that occur in a social learning context and are grounded in a social constructivist theoretical framework.

- In PA, the feedback process is used to optimally drive student learning, improvement, and ultimately growth. Vygotsky's theory of cognitive development promotes cognitive growth providing teachers with the opportunity to progressively assess learners' performance in the zone of proximal development (ZPD)

- The interweaving of learning tasks and assessment activities is sometimes called 'assessment as learning.' Assessment of and for learning can be constructively aligned and fully integrated with instructional theory and design, if they are to succeed in driving the learning and assessment process.

- An important aspect of PA is allowing or making the student assume agency and accountability for their own learning and their own assessment. Self-regulation theory (SRL) and self-determination theory (SDT) provide scaffold for students' autonomy and for the development of autonomy-supportive teaching.

Our aim was to explain the principles behind PA in a narrative way using various theories as an explanatory story.

Therefore, this article will briefly highlight key features of the PA model, and then we will delve into the main theoretical frameworks that scaffold critical elements of the model and finally will discuss opportunities and challenges of PA for teachers and learners highlighting future directions.

\section{Programmatic assessment: The model}

There are examples of various implementations of PA, each with their own individual slant. However, there are some more universal elements of PA that seem to work synergistically across time:

1. Training activities involve a series of learning tasks and are arranged in such a way that they contribute to create a curriculum based on principles of instructional design

2. Assessment activities are designed to be meaningful to the learner and to support ongoing learning and growth. They provide the teacher with multiple assessment data points from a wide array of assessment methods.
- The program uses multiple instruments deliberately based on how each individual method's strengths and weakness are combined synergistically.

- The assessment in PA is a continual and longitudinal process during which information about the learner's strengths, weaknesses, and progress is collected and collated.

- Information about the learner is not collated within instruments (such as the result on one station in an OSCE being combined with performance on another station) but purposefully triangulated across instruments (performance on the OSCE station with relevant information from another assessment method) to arrive at a meaningful "diagnosis" of competence.

- Decision-making is proportional; the stakes of an assessment decision are proportional to the richness of the information on which it is based.

- Quality and utility of the assessment process are determined by a variety of quality assurance processes, including standard psychometrics, member checking, saturation of information, stepwise replication, and expertise development.

- The focus is on keeping the information rich, for instance through collection in a portfolio, to enable holistic, as opposed to reductionist, assessment of competence.

- The initial focus is on using the assessment information on driving learning in a way that is meaningful to the learner rather than merely behaviorist.

- Successful learning and improvement are defined as becoming the best health professional each student can be, rather than being better than the other students.

- The focus is on identifying those learners who are unable or remain unwilling to accept and use feedback and demonstrate using it to drive their learning and to improve.

- In PA, the feedback loop has to be closed all the time.

- PA seeks to gradually increase the learner's agency and accountability for their own learning and progress, starting from rather structured and school-controlled assessment to self-owned assessment and learning.

a. The main task of the assessor is to provide feedback to the learner by utilizing the information from each data point and to make a decision about the progress of the learner also based on previous assessment information. Low-stake data point information can be later utilized by the assessor.

b. Assessment and training activities are very closely interrelated and sometimes, they may be the same. Most assessment tasks are developmental but some are mastery-oriented. A mastery-oriented task is high stakes, but it does still constitute an opportunity for feedback and may not be completely unrelated or unaffected by lowstakes activities.

3. Assessment activities happen therefore in a longitudinal fashion. There is a continuous process of collecting information - either through formal assessments or through informal and formal feedback - in a dossier or portfolio with periodic reflections and meetings with a faculty member/coach. The enactment on feedback by the learner is an integral part of the assessment.

4. Supporting activities include reflective and self-regulated learning. Reflective learning performed by learners is based on information from learning and assessment activities. Self-regulated learning is supported by faculty through students' coaching and mentoring. Social interaction provides a scaffold for reflective activities and self-regulated learning.

5. Intermediate and final evaluations are decision points interspersed throughout training and assessment activities across the continuum. Intermediate evaluations are remediation-oriented, provide information-rich 
recommendations for learning, and are aimed at the longitudinal development of the learner.

6. The final evaluation is a high-stakes decision with the goal of determining whether the learners can progress in the program or should exit. It is achieved by a committee of experts who make a judgment utilizing information from multiple data points and intermediate evaluations (Van der Vleuten et al. 2012).

\section{Theoretical frameworks}

\section{Fundamental PA principle: Meaning making}

Meaning and meaning making play a central role in PA. In PA meaning making, learners are required or incentivized to analyze and triangulate all information available to them, identifying specific strengths and weaknesses. As a result, learners actively construct meaning of the information, develop a new understanding of their performance, and design concrete plans for future learning. In order to be able to triangulate information across assessment methods, the teacher and learner must be able to see meaning in the way the information is combined - much like a clinician sees meaning in combining a lab result with a history taking response and a physical examination finding (Tweed and Wilkinson 2019). This meaning making is also important for the provision of constructive feedback and the formulation of useful and actionable learning goals. Several theories underpin why this would lead to better judgments and better learning.

\section{Explanatory theories: Constructivist and social constructivist}

In a constructivist approach, learning is seen as an active process of meaning making, positing that knowledge has to be constructed internally in order to be retained and accessible for future problem-solving. The theory states that further knowledge and understanding are constructions, which means that they have to be actively built on existing knowledge and understanding and are therefore not acquired passively. Learning is also seen as a social activity between stakeholders (learners and teachers) and teachers facilitate and support students' active involvement with the material (Dewey 1938; Bruner 1960; Vygotsky 1978; Bruner 1986). Interaction with the purpose of effective learning thus depends on shared meaning making between the stakeholders.

Social constructivism stresses the value of the social process in cognitive development and deep understanding. The critical interactions with others not only facilitate the building of new knowledge on existing knowledge but also make the learners construct and reconstruct their understanding. Thus, they create various meaningful perspectives on the learned knowledge and understanding through a social and collaborative setting. It emphasizes, therefore, the collaborative nature of learning and the importance of the cultural and social context in the learning process. This strengthening of cognitive processes originates in and is the result of social interactions. Learning is not only the assimilation of new knowledge by learners, but it is also the process by which learners become integrated into a knowledge community (Vygotsky 1978; Bruner 1986). Meaning making and meaningful interaction are therefore sine qua nons for these processes.

\section{Fundamental PA principle: Longitudinality}

The approach to collect information about the learner's progress longitudinally is important in PA as well. It provides a longer assessment engagement and thus more of a movie rather than a snapshot. Further, in accordance with the principle of proportionality (Schuwirth et al. 2017) in which the stakes of the decisions have to be proportional to the credibility, richness, and robustness of data, prolonged engagement allows for more time to collect and collate multiple assessments' data points and greater stakeholder numbers in relation to high stakes in decision making and it enables the assessment feedback to better build on previous feedback.

\section{Explanatory theories: Constructivist and social constructivist}

Dewey (1938), many decades ago, described the principle of continuity of experience in which every experience is shaped by the previous experience and 'modifies in some ways the quality of those which come after' (p. 27). Based on the principle of continuity, effective education is seen as a process of continuous growth and the quality of the experience is intended as a way to influence later experiences. The principle of continuity of experience is therefore an important aspect of PA in which assessment, training, and supporting activities are arranged to support ongoing learning.

This is further supported by the work of Vygotsky (1978) and Feuerstein et al. (2002) in which the concept of dynamic assessment, opposed to static assessment, is central. Dynamic assessment aims at the future development of the learner through a process of assisted performance. It is not merely about what the student can do at a certain point in time (more an assessment of learning perspective) but how the student could respond to feedback and assistance (assessment for learning). The emphasis is therefore not on what has been learned in the past but on what can be learned in the present and the future. In modern education, this is not an implausible expectation; with the increasing expectation of the lifelong learner, we realize that the - behaviorist - span of control ends with graduation and the university's responsibility to society starts with graduation. The arrangement of assessment activities to support and create learning with constant delivery of feedback to learners, the role of teachers in coaching and mentoring students, and the social interdependence and interactions among assessors in the setting of a committee of experts who make high or low stakes decisions are some of the elements of PA that occur in a social learning context and are grounded in a social constructivist theoretical framework.

In view of the importance of prior learning as an influence on new learning, PA includes key elements of pedagogic practice that allow knowledge restructuring to occur. PA creates the scaffold for the development of new knowledge structures and provides students with 
continuous opportunities to apply concepts and strategies in novel situations. In this context, teaching and assessment are blended toward the goals of learning, particularly the goal of closing gaps between current understanding and the new understandings sought. The combination of components of assessment for and of learning allows creating a continuous assessment across an educational continuum supported by multiple data points from different assessment practices and tools.

\section{Fundamental PA principle: Continuous feedback and closing the feedback loop}

In PA, a central role exists for the provision and uptake of feedback and closing the feedback loop. This is not to be confused with formative assessment; instead, it is about an approach in which the feedback process is used to optimally drive student learning. This means that the student has to take the feedback on board and has to demonstrate that the ensuing learning goals have led to the purported improvement. This means that the summative aspect in PA is not the attainment of a certain cutoff score in a one-off occasion but a continuous process of reaching mutually agreed upon targets which are also acceptable to the outside world. This is not an easy process for the learner and will often push them outside of their comfort zone. Various theories explain why this facilitates effective learning.

\section{Explanatory theories: Cognitivist and cognitive development orientation}

Assimilation theory (Ausubel 2012) and the theory of cognitive development (Vygotsky 1978) are important theoretical tenets of PA. Assimilation theory posits that new ideas are effectively learned when they are related to and assimilated by established ideas or notions, so that they can create a new cognitive structure. In PA, new data points are continually assimilated to previous 'established' data points, and assessment data are assimilated to previous established assessment data, leading to both the intermediate and final evaluation of the model.

In Vygotsky's theory of cognitive development, one central aim is to encourage cognitive growth by creating cognitive conflict, following Vygotsky's dictum from 'Mind in Society: the only good learning is that which is in advance of development' (Vygotsky 1978, p. 82). A key concept of the Vygotskian theory is the zone of proximal development (ZPD) which is intended as the space or distance between the actual and potential development of a learner. The ZPD represents an area in which learning and development interact and it provides a measure of developmental readiness. Challenging tasks that are in the ZPD promote maximum cognitive growth. Therefore, the opportunity for educators to progressively assess learners' performance in the ZPD, integrating longitudinal low- and high-stakes assessment information, may provide a new insight in $P A$ and deserves further exploration. The ZPD exists when the learner's existing conceptualizations about the world clash with new information, and this applies to self-conceptualizations about the learner's own competence as well.

This is similar to the disorientating dilemma as posited by Mezirow's transformative learning theory (Mezirow
2002), in which the disorientating dilemmas serve as a starting point for reframing understanding, both of the world around you and of yourself as a learner. The developmental structure and supporting activities of PA allow the interaction of students and teachers in the ZPD, therefore promoting cognitive development and cognitive change. We propose that the concept of the ZPD plays a key role in PA, encouraging cognitive growth and development.

\section{Fundamental PA principle: Assessment for learning and assessment as learning}

The PA as an assessment for learning approach is different from a more traditional approach in that the lines between educational and assessment processes are fuzzier. In the more traditional approaches, assessment can be seen as a process extrinsic to education, merely aimed at measuring the outcome of the educational process, whereas in PA, the assessment process is an inextricable part of education. This is perhaps the most difficult change in philosophical stance but there is, again, plausible theoretical underpinning of why PA supports the development of learner competence, likely even better than traditional assessment.

\section{Explanatory theories: Theory of instructional design and constructivist orientation}

The interweaving of learning tasks and assessment activities is sometimes called 'assessment as learning.' A learning task may involve a number of learning activities leading to learning: a TBL or PBL small group tutorial, a self-study, a lecture, a history and physical exam write up, or a problem-solving assignment. Learning task analysis involves the identification of prerequisite competencies which are needed to achieve target and enabling objectives (Gagne et al. 2005). A purposeful selection of tasks in the program is then required; learning tasks are set to support the student in acquiring necessary basic knowledge, skills, or understanding to serve as a springboard to reach target objectives or promote further and deeper learning. This principle does not only pertain to the acquisition of medical competence but also to learning how to learn. In $\mathrm{PA}$, the continuous feedback and requirement for the learner to make meaning, in conjunction with the expectation that the learner will use this to formulate and successfully enact learning goals, are to be seen as learning tasks on 'learning to learn.' The concept of learning tasks of PA is plausibly grounded in Gagne's analysis of learning tasks. In other words, not only are training activities and assessment activities closely connected, but also are learning for medical competence and learning to learn.

Similarly, Merriënboer and Kirschner (2017) describe a ten-step and 4C/ID (4 components instructional design) model. One of the main and first component of this model entails the design of learning tasks. Similar to the PA model, the structural elements of 4C/ID model are interdependent and the design of performance assessments allows to measure performance on each of the tasks, at particular points in time. This allows for monitoring the learners' longitudinal progression over the leaning tasks. Further, one of the steps involves the sequence of learning 
tasks (step 3), from simple to more complex, which, coupled with frequent performance assessments (step 2), optimizes learning and creates individualized learning developmental trajectories. In the 4C/ID model, Van Merriënboer and Kirschner (2017) contend that even though the summative focus of assessment (assessment of learning) is to make high-stakes decisions, it must also perform a strong formative - meaningful feedback - function. Therefore, assessment of and for learning can be constructively aligned, and fully integrated with instructional theory and design, if they are to succeed in driving the learning and assessment process, but how successful this can be done depends on the quality of the teacher or coach and the learning culture in the organization (Harrison et al. 2016, 2017). In PA, multiple assessments are tightly linked and connected with a variety of learning (training) activities embedded in a rich social learning context aimed at supporting the student growth throughout the educational continuum.

\section{Fundamental PA principle: Student agency and accountability}

An important aspect of PA is allowing or making the student assume agency and accountability for their own learning and their own assessment. As said before, the span of - behaviorist - control over the learners' learning and assessment ends with their graduation but the medical school's responsibility to society starts with graduation. PA programs therefore seek to gradually hand over that agency and accountability to the learner. This implies that a conscious and purposeful balance between behaviorist and self-regulation theory-informed drivers is part of the implementation.

\section{Explanatory theories: Self-determination theory (SDT) and self-regulation learning theory (SRL)}

Supporting activities, in particular the concept of 'autonomy-supportive teaching,' are a key component of the PA model and involve learners and teachers. Such 'autonomy-supportive teaching' is grounded in, among others, two theoretical frameworks, SDT and SRL.

One of the main pillars of SDT is the concept of or need for autonomy. In SDT, autonomy is intended as 'being the perceived origin or source of one's own behaviour' (Deci and Ryan 2004, p. 8) and therefore, an autonomous behavior is an expression of the self. In SDT, autonomy-supportive teachers provide opportunities for independent work and support internal motivations, and they are flexible and responsive to the needs of the students. Therefore, 'autonomy-supportive teaching' is a major role teachers play in the context of PA, and the coaching fosters students' self-determination and helps move the students across an autonomy continuum. This theoretical perspective fits with the perspectives in the previous paragraphs that illustrated how PA processes aim to create cognitive understanding of the meaning of learning-to-learn as an ongoing and lifelong learning process.

In order to be able to achieve the desired autonomy needed for successful lifelong learners, self-regulated learning (SRL) can be insightful (Pintrich 2004; Schunk 2005).
SRL posits that learners are involved in goal setting, selecting learning strategies and evaluating their own performance. The concept of 'autonomy-supportive teaching' is also grounded in the principle of socially regulated learning in which the teacher helps the student in setting goals, suggesting learning tasks, monitoring and assessing the learning process (Zimmerman 1998; Bandura 2001).

This however does not come naturally to almost all learners and must often be gradually developed. Initially, the drivers behind assessment may need to be more external and may not be internalized yet.

\section{Explanatory theories: Behaviorist orientation and principles of deliberate practice}

Tenets of behaviorist approaches are considered when we encounter the concept of mastery learning in PA (Block 1980; Guskey 1980; Skinner 2011). In mastery learning, students cannot progress to the next level of instruction unless they demonstrate a set level of proficiency. This mastery can pertain to elements of medical competence but also to elements of learning to learn. For example, producing reflection or self-analyses documents may need to be learned through a series of programed exercises. For all these aspects, the concept of shaping, where instruction proceeds with tasks of increasing levels of difficulty, coupled with immediate reinforcement and feedback is a principle of the behaviorist orientation.

Mastery learning is a key principle of deliberate practice for some aspects - typically the more technical aspects as is meaning making to others - typically the more understanding/insight-related aspects. Deliberate practice is intended as the activity designed by a coach to improve performance of an individual through repetition and refinement (Anders Ericsson 2008). Learners' motivation and the design of the task are crucial elements of deliberate practice. Educators should take into account the pre-existing knowledge and understanding of the learners, so that the task can be correctly understood after a brief period of instruction.' Learners should receive immediate relevant feedback and knowledge of results of their performance after each task-related activity. Principles of deliberate practice such as task design, repeated practice under supervision, and relevant feedback are crucial to the development of the learner in the setting of PA.

Further, according to the Vygotskian perspective, teacher and student will have to engage in co-regulated learning, in which they share the responsibility of shaping and directing the learning process but with a gradual change of responsibilities. For this, the initial scaffold will be slowly removed and the student is expected to gradually take increasing responsibility of his or her own learning, developing self-regulating skills (van Houten-Schat et al. 2018). In PA, the relationship of student and teacher is crucial, and one role of PA might indeed be that of foster self-regulation of students at different stages of their development.

\section{Explanatory theories: Job demand-resource theory}

In the job demand-resource theory (JDR-T) (Bakker and Demerouti 2017), job characteristics fall into two main 
broad categories: job demands and job resources. Job demands are physical psychological and organizational efforts that may include high work pressure or emotionally demanding situations. Job resources are those aspects of the job that reduce job demands, foster autonomy, provide feedback on performance, promote personal growth, and achieve work goals. Job resources predict future work engagement and motivation. In PA assessment, the role of the faculty within the supporting activities may be similar to that of creating job resources as defined by Bakker and Demerouti (2017). Faculty when acting as coaches contribute to develop students' self-determination and autonomy, foster an interactive social learning environment, and strive to provide those job resources that allow students to cope with job demands while creating opportunities for development and growth.

\section{Discussion}

Unlike in medical research, medical education research does not automatically assume perfect replication of research findings. So, where medical research is often aimed at producing findings that can be replicated in any other context regardless of contextual features - typically like randomized controlled trials - often (medical) education research starts from the assumption of complexity or systems (Rosas 2015). In complex situations, direct replication of findings from one context to another does not work; instead, there is a need to understand why something works so it can be adapted or transferred to fit another, slightly different context. Such understanding can be seen as analogous to the role of a deep structure in transfer of problem solving (Eva et al. 1998). Theory can therefore help overcome the challenges of implementation that may arise in specific contexts or learning organizations (Torre et al. 2006).

As far as theory informed opportunities for the implementation of PA, we like to illustrate an example of how theory may help face an implementation challenge. For instance, when students are in their clinical rotations, they might have issues during one rotation. It is then imperative that the supervisor/coordinator of future rotations knows about these issues, so that they can specifically support the student with these during the subsequent rotations. However, notifying that supervisor may be perceived by the students as an unfair transfer of a 'criminal case record' and therefore may be seen to be biasing the next supervisor. From a PA view, it would be more like a 'continuity of care' process. This dilemma is a major one in a standard assessment of learning context, but it is an easy one to solve in a PA context. The student who experiences issues during one rotation is asked to analyze - together with their learning coach - and provide a plan for remediation. The student is then expected to communicate and discuss this plan with their future supervisor and make arrangements for how to implement this plan. As a check, it can be required that the supervisor signs a plan and it becomes part of the portfolio. The student and their learning coach could also discuss and practice the way the student would communicate their issues with their future supervisor/coordinator, as a way of allowing the student to learn how to deal with these difficult conversations. As such, continuity of care and longitudinality of information is safeguarded, agency lies with the student for their own learning, the issues in the past rotation are not merely bad experiences but opportunities for learning, and the issues are not just a tick box on an academic transcript, but are being used to optimize meaning making of learning, foster self-regulated learning, and promote continuous growth and learner's development.

In this article, we have tried to build a narrative story linking most recognizable education and learning theories to PA. We have chosen for such a narrative style because we aimed at providing optimal avenues for coherent meaning making by the reader.

From our narrative, we think it is clear that there are multiple theoretical perspectives that underpin the central aspects of PA and that in doing so there seems to be significant overlap in theories. For example, Vygotsky's (1978) ZPD and Mezirow's (2002) disorientating dilemma both align when we try to explain the function of the critical self-analysis of the learner's own progression and the discussion with a coach who will aim to push the learner out of their comfort zone.

What we have not addressed and what is increasingly being recognized as a significant issue is the role of organizational culture and of so-called naïve epistemologies. The former is significant in that it facilitates or hampers the willingness in the organization to change (Harrison et al. 2017). The latter is even more difficult to overcome, as it relates to the deep beliefs, we develop about the world around us by unsystematic and unguided experience (Vosniadou 1994). This phenomenon often leads people to believe that the way they were educated and assessed should be the mold for modern education. However, like we do not practice medicine like we did 50 years ago, neither should we aim at practicing education the way we did 50 years ago. Why there is a general natural professional tendency in medicine to progress and when it comes to medical education to be conservative is still unclear. We felt that there is not sufficient theoretical development in this field yet to include this element in our narrative.

Another aspect of PA that we have not covered is the necessity of the stakeholders in the process to be well trained, or sufficiently assessment literate (Popham 2009). Although there is emerging research on the 'diagnosing' of dyscompetence (Govaerts et al. 2011, 2012; Valentine and Schuwirth 2019) and on the narratives around providing judgments and feedback (Ginsburg et al. 2015; Cook et al. 2016; Ginsburg et al. 2017), we felt that this aspect too requires further theory building before including it in this narrative to illustrate the tenets of PA.

At this point, we want to restate that we did not set out to compare the explanatory power of various theories with each other, nor did we want to claim that our choice of theories is the best. Instead, we were aiming at constructing a plausible, logical, and coherent narrative linking educational and learning theories to the fundamental principles of PA (for learning).

\section{Disclosure statement}

The authors report no conflicts of interest. The authors alone are responsible for the content and writing of this article. 


\section{Notes on contributors}

Dario M. Torre, MD, MPH, PhD, is an Professor of Medicine and Associate Director for Program Evaluation and Long Term Outcomes at Uniformed Services University of Health Sciences in Bethesda, Maryland, USA.

L. W. T. Schuwirth, MD, PhD, is Professor of Medical Education, Health Profession Education, Flinders Medical School, Adelaide, South Australia.

C. P. M. van der Vleuten, $\mathrm{PhD}$, is Professor of Education and Chair of the Department of Educational Development and Research and Scientific Director of the School of Health Professions Education, Faculty of Health Medicine and Life Sciences, Maastricht University, The Netherlands.

\section{ORCID}

L. W. T. Schuwirth (iD http://orcid.org/0000-0002-6279-5158

C. P. M. Van der Vleuten (iD http://orcid.org/0000-0001-6802-3119

\section{References}

Anders Ericsson K. 2008. Deliberate practice and acquisition of expert performance: a general overview. Acad Emerg Med. 15(11):988-994.

Ausubel DP. 2012. The acquisition and retention of knowledge: a cognitive view. Berlin (Germany): Springer Science \& Business Media.

Bakker AB, Demerouti E. 2017. Job demands-resources theory: taking stock and looking forward. J Occup Health Psychol. 22(3):273.

Bandura A. 2001. Social cognitive theory: an agentic perspective. Annu Rev Psychol. 52(1):1-26.

Biggs J. 1996. Enhancing teaching through constructive alignment. High Educ. 32(3):347-364.

Block JH. 1980. Promoting excellence through mastery learning. Theory Pract. 19(1):66-74.

Bok HG, Teunissen PW, Favier RP, Rietbroek NJ, Theyse LF, Brommer H, Haarhuis JC, van Beukelen P, van der Vleuten CP, Jaarsma DA. 2013. Programmatic assessment of competency-based workplace learning: when theory meets practice. BMC Med Educ. 13(1):123.

Bruner J. 1960. The process of education. Cambridge (MA): Harvard University Press.

Bruner J. 1986. Actual minds, possible worlds. Cambridge (MA): Harvard University Press.

Cianciolo AT, Eva KW, Colliver JA. 2013. Theory development and application in medical education. Teach Learn Med. 25(1):s75-s80.

Cook DA, Kuper A, Hatala R, Ginsburg S. 2016. When assessment data are words: validity evidence for qualitative educational assessments. Acad Med. 91(10):1359-1369.

Deci EL, Ryan RM. 2004. Handbook of self-determination research. Rochester (NY): University of Rochester Press.

Dewey J. 1938. Experience and education. New York (NY): Collier Books

Driessen EW, Van Tartwijk J, Govaerts MJ, Teunissen P, van der Vleuten CP. 2012. The use of programmatic assessment in the clinical workplace: a Maastricht case report. Med Teach. 34(3):226-231.

Eva KW, Neville AJ, Norman GR. 1998. Exploring the etiology of content specificity: factors influencing analogic transfer and problem solving. Acad Med. 73(10):s1-s5.

Feuerstein R, Feuerstein RS, Falik LH, Rand YA. 2002. The dynamic assessment of cognitive modifiability: the learning propensity assessment device: theory, instruments and techniques. Jerusalem (Israel): ICELP Publications.

Gagne RM, Wager WW, Golas KC, Keller JM, Russell JD. 2005. Principles of instructional design. Nonprofit Manag Leader. 44(2):44-46.

Ginsburg S, Regehr G, Lingard L, Eva K. 2015. Reading between the lines: faculty interpretations narrative evaluation comments. Med Educ. 49(3):296-306.

Ginsburg S, Vleuten CP, Eva KW, Lingard L. 2017. Cracking the code: residents' interpretations of written assessment comment. Med Educ. 51(4):401-410.

Govaerts MJ, Schuwirth LWT, Van der Vleuten CP, Muijtjens AM. 2011 Workplace-based assessment: effects of rater expertise. Adv Health Sci Educ. 16(2):151-165
Govaerts MJ, Van de Wiel MWJ, Schuwirth LWT, Van der Vleuten CPM, Muijtjens AM. 2012. Workplace-based assessment: raters' performance theories and constructs. Adv Health Sci Educ. 18(3):1-22.

Guskey TR. 1980. Mastery learning: applying the theory. Theory Pract. 19(2):104-111.

Harrison CJ, Könings KD, Dannefer EF, Schuwirth LWT, Wass V, van der Vleuten C. 2016. Factors influencing students' receptivity to formative feedback emerging from different assessment cultures. Perspect Med Educ. 5(5):276-284.

Harrison CJ, Könings KD, Schuwirth LWT, Wass V, van der Vleuten C. 2017. Changing the culture of assessment: the dominance of the summative assessment paradigm. BMC Med Educ. 17(1):73.

Heeneman S, Schut S, Donkers J, van der Vleuten CP, Muijtjens AM. 2017. Embedding of the progress test in an assessment program designed according to the principles of programmatic assessment Med Teach. 39(1):44-52.

Jamieson J, Jenkins G, Beatty S, Palermo C. 2017. Designing programmes of assessment: a participatory approach. Med Teach. 39(11):1182-1188.

Lewin K. 1951. Field theory in social science: selected theoretical papers. New York (NY): Harper \& Row.

Merriënboer JJ, Kirschner PA. 2017. Ten steps to complex learning: a systematic approach to four-component instructional design. Abingdon (UK): Routledge.

Mezirow J. 2002. Transformative learning: theory to practice. New Dir Adult Cont Educ. 74:5-12.

Olupeliyawa A, Balasooriya C. 2015. The impact of programmatic assessment on student learning: what can the students tell us? Med Educ. 49(5):453-456.

Pintrich PR. 2004. A conceptual framework for assessing motivation and self-regulated learning in college students. Educ Psychol Rev. 16(4):385-407.

Popham WJ. 2009. Assessment literacy for teachers: faddish or fundamental? Theory Pract. 48(1):4-11.

Prochaska JO, Wright JA, Velicer WF. 2008. Evaluating theories of health behavior change: a hierarchy of criteria applied to the trans theoretical model. Appl Psychol. 57(4):561-588.

Roberts C, Shadbolt N, Clark T, Simpson P. 2014. The reliability and validity of a portfolio designed as a programmatic assessment of performance in an integrated clinical placement. BMC Med Educ. 14(1):197.

Rosas SR. 2015. Systems thinking and complexity: considerations for health promoting schools. Health Promot Int. 32(2):301-311.

Schunk DH. 2005. Self-regulated learning: the educational legacy of Paul R. Pintrich. Educat Psychol. 40(2):85-94.

Schuwirth LWT, Valentine N, Dilena P. 2017. An application of programmatic assessment for learning (PAL) system for general practice training. GMS J Med Educ. 34(5):Doc56. DOI:10.3205/ zma001133.

Schuwirth LWT, Van der Vleuten C. 2011. Programmatic assessment: from assessment of learning to assessment for learning. Med Teach. 33(6):478-485.

Skinner BF. 2011. About behaviorism. New York (NY): Vintage Books.

Torre DM, Daley BJ, Sebastian JL, Elnicki DM. 2006. Overview of current learning theories for medical educators. Am J Med. 119(10):903-907.

Tweed M, Wilkinson T. 2019. Student progress decision-making in programmatic assessment: can we extrapolate from clinical decisionmaking and jury decision-making? BMC Med Educ. 19(1):176.

Valentine N, Schuwirth L. 2019. Identifying the narrative used by educators in articulating judgement of performance. Perspect Med Educ. 8(2):1-7.

Van der Vleuten CPM, Schuwirth L. 2005. Assessing professional competence: from methods to programmes. Med Educ. 39(3):309-317.

Van der Vleuten CPM, Schuwirth LWT, Driessen EW, Dijkstra J, Tigelaar D, Baartman LKJ, van Tartwijk J. 2012. A model for programmatic assessment fit for purpose. Med Teach. 34(3):205-214.

van Houten-Schat MA, Berkhout JJ, van Dijk N, Endedijk MD, Jaarsma $A D$, Diemers AD. 2018. Self-regulated learning in the clinical context: a systematic review. Med Educ. 52(10):1008-1015.

Vosniadou S. 1994. Capturing and modeling the process of conceptual change. Learn Instruct. 4(1):45-69.

Vygotsky LS. 1978. Mind in society. Cambridge (MA): Harvard University Press. 
Wilkinson TJ, Tweed MJ, Egan TG, Ali AN, McKenzie JM, Moore M, Rudland JR. 2011. Joining the dots: conditional pass and programmatic assessment enhances recognition of problems with professionalism and factors hampering student progress. BMC Med Educ. 11(1):29.
Zimmerman BJ. 1998. Developing self-fulfilling cycles of academic regulation: an analysis of exemplary instructional models. In: Schunk DH, Zimmerman BJ, editors. Self-regulated learning: from teaching to self-reflective practice. New York (NY): Guilford Press; $p$. $1-19$. 